\title{
Expanding the applications of transcatheter aortic valve replacement: Wave of the future, or not so fast?
}

\author{
Suk Jung Choo, MD, PhD
}

From the Thoracic and Cardiovascular Surgery, Asan Medical Center, Ulsan University School of Medicine, Seoul, Republic of Korea.

Disclosures: Author has nothing to disclose with regard to commercial support.

Received for publication May 12, 2017; accepted for publication May 18, 2017; available ahead of print July 1, 2017.

Address for reprints: Suk Jung Choo, MD, PhD, Thoracic and Cardiovascular Surgery, Asan Medical Center, Ulsan University School of Medicine, 388-1 Poongnap-dong, Songpa-gu, Seoul 138-736, Republic of Korea (E-mail: sjchoo@amc.seoul.kr).

J Thorac Cardiovasc Surg 2017;154:818-9

$0022-5223 / \$ 36.00$

Copyright $\subset 2017$ Published by Elsevier Inc. on behalf of The American Association for Thoracic Surgery http://dx.doi.org/10.1016/j.jtcvs.2017.05.063

In this issue of the Journal, Greason and colleagues ${ }^{1}$ report their experience with transcatheter aortic valve replacement (TAVR) in patients who had previously undergone mitral valve surgery (mitral valve replacement, $\mathrm{n}=4$ patients; mitral valve repair, $\mathrm{n}=4$ patients). The increasing acceptance of TAVR as an alternative to high-risk surgical aortic valve replacement (SAVR) has been supported by the Placement of Aortic Transcatheter Valves trial (PARTNER) and subsequent related studies. ${ }^{2,3}$ Investigators have sought to expand the indications of TAVR to apply it to increasingly more difficult and complex situations, such as in patients with severe aortic stenosis and previous mitral valve surgery. ${ }^{4}$ Avoiding a reoperative sternotomy would significantly reduce the surgical risk, especially in elderly patients with a high frailty index and major preexisting comorbidities. At issue, however, is whether the previous mitral valve prosthesis might somehow interfere with the transcatheter procedure or whether the mitral prosthesis would itself somehow be adversely affected by the TAVR. Soon and colleagues ${ }^{5}$ raised concerns regarding the possibility of valvuloplasty balloon shifts being caused by the bioprosthetic strut or the mechanical valve pivot guards, leading to malpositioning during transcatheter aortic valve deployment and to valve dysfunction. Complications reported in previous case studies related to underexpansion of the transcatheter valve prostheses ${ }^{6,7}$ were among the concerns that Greason and colleagues ${ }^{1}$ had indicated regarding this approach. Possible injury to the conduction system, eventually leading to complete heart block and need for permanent pacemaker (PPM) implantation, is also a concern that should be considered. This is especially pertinent because a successful TAVR in these patients is in effect a double valve replacement (aortic and mitral valve replacement), which is a known significant predictor of postoperative complete heart block and PPM insertion (odd ratio, 11.5; $P=.027$ ). ${ }^{8,9}$ These concerns notwithstanding, Greason and colleagues ${ }^{1}$

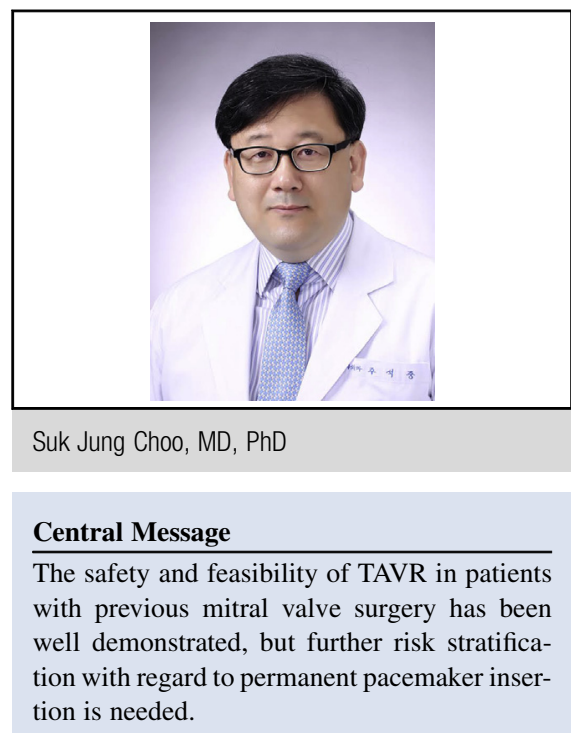

See Article page 810 .

reported excellent outcomes, with no significant mitral or transcatheter aortic valve dysfunction, no paravalvular leakage greater than moderate, no significant transprosthetic aortic valve pressure gradient, no outcome differences between different manufacturers (CoreValve vs SAPIEN valve), no early mortality, and $100 \%$ procedural success, with follow-up extending to 1 year in duration. Of concern, however, are the 2 intermediateterm deaths of unknown causes at 0.7 years and 1.4 years, which unless proved otherwise cannot definitively be considered non-valve related in origin. Furthermore, the new PPM insertion rate, which was reportedly not significantly greater in the patients undergoing TAVR with a history of previous mitral valve surgery than in those without such a history $(P=.491)$, may actually be significantly greater than thought because of the underpowering by the small sample size. When combining the 8 preexisting PPMs with the 3 new PPMs, the total number of patients with PPMs amounts to 11 of the 18 patients, or $61 \%$ of the total patients. This is not to mention, however, a whole array of already known risk factors for TAVR-associated PPM insertion, such as the amount of device landing zone calcification, ${ }^{10}$ the left ventricular outflow tract calcium below the left and right coronary cusp, ${ }^{11}$ and baseline right $^{12}$ or left ${ }^{13}$ bundle branch block, to name just a few obvious high-profile risk factors. Considering that metaanalyses have shown significantly greater PPM insertion 
rates in patients undergoing TAVR versus SAVR, ${ }^{14,15}$ all these issues that may come into play in addition to the existing risks should be carefully weighed when contemplating the entire spectrum of risk to benefit of performing TAVR in these cases. On a final note, the study of Greason and colleagues ${ }^{1}$ is a retrospective review limited to 18 patients, and although safety and reproducibility were clearly demonstrated in their hands, SAVR outcomes are also reportedly excellent, warranting further studies to demonstrate sufficient evidence to stratify the application of TAVR or SAVR in patients with previous mitral valve surgery as they apply individually.

\section{References}

1. Greason KL, Sandhu GS, Nkomo VT, King KS, Joyce DL, Williamson EE, et al. Transcatheter aortic valve insertion after previous mitral valve operation. $J$ Thorac Cardiovasc Surg. 2017;154:810-5.

2. Kapadia SR, Leon MB, Makkar RR, Tuzcu EM, Svensson LG, Kodali S, et al. 5year outcomes of transcatheter aortic valve replacement compared with standard treatment for patients with inoperable aortic stenosis (PARTNER 1): a randomised controlled trial. Lancet. 2015;385:2485-91.

3. Smith CR, Leon MB, Mack MJ, Miller DC, Moses JW, Svensson LG, et al; PARTNER Trial Investigators. Transcatheter versus surgical aortic-valve replacement in high-risk patients. N Engl J Med. 2011;364:2187-98.

4. Beller CJ, Bekeredjian R, Krumsdorf U, Leipold R, Katus HA, Karck M, et al. Transcatheter aortic valve implantation after previous mechanical mitral valve replacement: expanding indications? Heart Surg Forum. 2011;14: E166-70.

5. Soon JL, Ye J, Lichtenstein SV, Wood D, Webb JG, Cheung A. Transapical transcatheter aortic valve implantation in the presence of mitral prosthesis. J Am Coll Cardiol. 2011:58:715-21.
6. Sarkar K, Speciale G, Ussia GP. CoreValve implant failure in the presence of mechanical mitral prosthesis: importance of assessing left ventricular outflow tract. Catheter Cardiovasc Interv. 2015;85:920-4.

7. Testa L, Gelpi G, Bedogni F. Transcatheter aortic valve implantation in a patient with mechanical mitral prosthesis: a lesson learned from an intraventricular clash. Catheter Cardiovasc Interv. 2013:82:E621-5.

8. Bleiziffer S, Ruge H, Hörer J, Hutter A, Geisbüsch S, Brockmann G, et al. Predictors for new-onset complete heart block after transcatheter aortic valve implantation. JACC Cardiovasc Interv. 2010;3:524-30.

9. Huynh H, Dalloul G, Ghandbari H, Burke P, David M, Daccarett M, et al. Permanent pacemaker implantation following aortic valve replacement: current prevalence and clinical predictors. Pacing Clin Electrophysiol. 2009;32:1520-5.

10. Latsios G, Gerckens U, Buellesfeld L, Mueller R, John D, Yuecel S, et al. "Device landing zone" calcification, assessed by MSCT, as a predictive factor for pace-maker implantation after TAVI. Catheter Cardiovasc Interv. 2010;76:431-9.

11. Mauri V, Reimann A, Stern D, Scherner M, Kuhn E, Rudolph V, et al Predictors of permanent pacemaker implantation after transcatheter aortic valve replacement with the SAPIEN 3. JACC Cardiovasc Interv. 2016;9: 2200-9.

12. Nazif TM, Dizon JM, Hahn RT, Xu K, Babaliaros V, Douglas PS, et al; PART NER Publications Office. Predictors and clinical outcomes of permanent pacemaker implantation after transcatheter aortic valve replacement: the PARTNER (Placement of AoRtic TraNscathetER Valves) trial and registry. JACC Cardiovasc Interv. 2015;8:60-9.

13. Siontis GC, Jüni P, Pilgrim T, Stortecky S, Büllesfeld L, Meier B, et al. Predictors of permanent pacemaker implantation in patients with severe aortic stenosis undergoing TAVR: a meta-analysis. J Am Coll Cardiol. 2014;64:129-40.

14. Kondur A, Briasoulis A, Palla M, Penumetcha A, Mallikethi-Reddy S, Badheka A, et al. Meta-analysis of transcatheter aortic valve replacement versus surgical aortic valve replacement in patients with severe aortic valve stenosis. Am J Cardiol. 2016;117:252-7.

15. Garguilo G, Sannino A, Capodanno D, Barbanti M, Buccheri S, Perrino C, et al. Transcatheter aortic valve implantation versus surgical aortic valve replacement: a systematic review and meta-analysis. Ann Intern Med. 2016;165:334-44. 